\title{
Almond Fruit Drop Patterns under Mediterranean Conditions
}

\author{
Jaume Lordan ${ }^{1, *}$, Lourdes Zazurca $^{1}$, Mercè Rovira ${ }^{2}$, Laura Torguet ${ }^{1}$, Ignasi Batlle ${ }^{2}$, Theodore DeJong ${ }^{3}$ \\ and Xavier Miarnau ${ }^{1}$ (D) \\ 1 IRTA Fruitcentre, PCiTAL, Park of Gardeny, Fruitcentre Building, 25003 Lleida, Spain; \\ lourdes.zazurca@irta.cat (L.Z.); laura.torguet@irta.cat (L.T.); xavier.miarnau@irta.cat (X.M.) \\ 2 IRTA Mas Bové, Ctra. Reus-El Morell Km 3, 8, 43120 Constantí, Spain; merce.rovira@irta.cat (M.R.); \\ ignasi.batlle@irta.cat (I.B.) \\ 3 Department of Plant Sciences, University of California, Davis, CA 95616, USA; tmdejong@ucdavis.edu \\ * Correspondence: jaume.lordan@irta.cat
}

Citation: Lordan, J.; Zazurca, L.; Rovira, M.; Torguet, L.; Batlle, I.;

DeJong, T.; Miarnau, X. Almond Fruit Drop Patterns under Mediterranean Conditions. Agriculture 2021, 11, 544. https:/ / doi.org/10.3390/agriculture 11060544

Academic Editors: Kourosh Vahdati, Anita Solar and Neus Aletà

Received: 14 April 2021

Accepted: 8 June 2021

Published: 12 June 2021

Publisher's Note: MDPI stays neutral with regard to jurisdictional claims in published maps and institutional affiliations.

Copyright: (C) 2021 by the authors. Licensee MDPI, Basel, Switzerland. This article is an open access article distributed under the terms and conditions of the Creative Commons Attribution (CC BY) license (https:/ / creativecommons.org/licenses/by/ $4.0 /)$.

\begin{abstract}
Almond is an important tree nut crop worldwide, and planted areas have been increasing year after year. While self-fertility is one of the key factors when it comes to improved almond productivity of new cultivars, yield is also affected by the number of flowers produced, pollination, fruit set, fruit drop, and fruit weight. Almond fruit drop patterns of 20 Mediterranean almond cultivars were studied over three years. In addition, fruit drop patterns of two scion cultivars 'Marinada' and 'Vairo' budded onto eight to 10 different rootstocks managed with three different pruning strategies were studied for two years. Cumulative flower and fruit drop ranged from $50 \%$ to $90 \%$ among cultivars and treatments, and there were up to four fruit drop events during the growing season, the main one occurring from 20-60 days from full bloom (DFFB). Subsequent drops were at 100 DFFB, 120-140 DFFB, and the last one at 160-180 DFFB. The later drops were less apparent. In general, about half of the cumulative drop was comprised of buds and flowers, and the remaining percentage was fruit that dropped 20 or more days after full bloom. Furthermore, different fruit drop patterns were observed depending on the cultivar. For late- and extra-late flowering cultivars, cumulative fruit drop began to decrease earlier, with most of the drops occurred already at full bloom, whereas the opposite was observed for the early flowering cultivars. Rootstocks also had an important effect on the fruit drop pattern, with different effects depending on the scion cultivar. Tree management, such as type of pruning, also had an important effect on the rate of fruit drop and cumulative drop. Therefore, each combination of cultivar $\times$ rootstock $\times$ pruning type will require different strategies in order to reduce the fruit drop and optimize crop loads.
\end{abstract}

Keywords: biennial bearing; bloom; cultivar; fruit set; pruning; rootstock; tree management; yield

\section{Introduction}

Almond (Prunus dulcis (Mill.) D. A. Webb. syn. Prunus amygdalus Batsch) is an important tree nut crop in terms of commercial production worldwide, and due to the release of new cultivars that provide late blooming times and self-fertility, the planted area has been increasing in recent years [1-3]. Regarding production, the USA is currently in the lead, with $79 \%$ of the world's production, followed by recent exponential growth in Australia (7\%), and then Spain in third place, with a harvest volume that accounts for $6 \%$ of the world total [4-6]. However, considering production surface, Spain has the largest growing area with $657,768 \mathrm{ha}$, followed by the USA with 628,000 ha, and Australia with 53,014 ha [4-6]. Currently, 86\% of the almond growing area in Spain is not irrigated, and in many cases on drylands with less than $300 \mathrm{~mm}$ of annual rainfall. Therefore, in these large areas, yearly productivity is still very low and in many cases does not exceed $100 \mathrm{~kg}$ of kernel.ha-1 $[6,7]$.

The reproductive process in almond trees spans two years from flower bud induction to fruit set and fruit maturity [1,8], and while there is substantial knowledge on the 
American traditional almond cultivars such as 'Nonpareil', there is lack of knowledge about the newly bred cultivars grown in Mediterranean areas. In addition to the planting of recently released cultivars, increasingly Mediterranean orchards are being irrigated, thus a better knowledge about almond tree behavior under these growing conditions is required.

While self-fertility is one of the key factors when it comes to improved almond productivity of new cultivars, yield is also dependent on the number of flowers produced, the percentage of flowers that set fruit, and fruit weight [8]. These yield components are genotype dependent and are influenced by environmental and management conditions [1,8-12].

Fruit set of almond flowers can range between $15-40 \%$, with most of the orchards having average fruit set between $20-30 \%$ [1,13]. In addition, three periods of flower/fruit drop have been described for the 'Nonpareil' cultivar in California [14]. The first drop takes place during bloom or shortly thereafter, the second drop occurs about a month after bloom, and the third drop takes place six to seven weeks after bloom [14]. However, since these drops seem to be driven by genetic and environmental factors that affect carbohydrate and hormone balances $[1,8,11,14]$, it is likely that the large number of cultivars recently released, from various and different genetic origins, may have different drop patterns. Hence, management should be specifically adapted to each combination of cultivar $x$ rootstock in order to optimize productivity and enhance orchard profitability.

The aim of this study was to assess the fruit drop patterns of 20 of the most popular almond cultivars grown in the Mediterranean areas. In addition, fruit drop patterns of 'Marinada' and 'Vairo' cultivars budded onto eight to ten different rootstocks and managed with different types of pruning were also examined.

\section{Materials and Methods}

\subsection{Orchards and Experimental Design}

The study was performed over either two or three years on mature almond trees in three different orchards (P1, P2, and P3) planted at the Experimental Station of IRTA (Institute of Research and Technology, Food and Agriculture) in Les Borges Blanques, northeastern Spain $\left(41^{\circ} 30^{\prime} 31.89^{\prime \prime} \mathrm{N} ; 0^{\circ} 51^{\prime} 10.70^{\prime \prime} \mathrm{E}\right)$. The P1 orchard was planted in 2009, using bare-root trees ( $1 \mathrm{~m}$ in height), with twenty different almond cultivars. Among the cultivars included, fifteen were from three different Spanish breeding programs: seven from IRTA (self-compatible: 'Constanti', 'Francoli', 'Marinada', and 'Vairo'; and selfincompatible: 'Glorieta', 'Masbovera', and 'Tarraco') [15,16]; four self-compatible cultivars from CITA ('Belona', 'Guara', 'Mardía', and 'Soleta') [3,17-19]; and four self-compatible cultivars from CEBAS-CSIC ('Antoñeta', 'Marta', 'Penta', and 'Tardona') [20,21]. Two other cultivars were obtained at INRA, France ('Ferragnès' self-incompatible, and 'Lauranne' self-compatible) [22,23]. Two traditional Spanish self-incompatible cultivars, 'Desmayo Largueta' and 'Marcona' [24], and one Italian self-compatible cultivar commonly planted in some Mediterranean countries, 'Tuono' [17,24], were also included in the study. All cultivars are considered hard-shelled and were budded onto INRA GF-677 rootstock [25]. Trees were planted in a randomized complete block design, with four replications and with each block containing four trees of each cultivar. Trees were trained to a central axis system, with a tree spacing of $4.5 \mathrm{~m} \times 2 \mathrm{~m}$.

The P2 orchard was planted with dormant budded trees in 2010 using 'Marinada' and 'Vairo' as the scion cultivars. These cultivars were selected due to their late-flowering and self-fertility, and their different vegetative and productive habits; 'Marinada' being a medium-weak vigor cultivar, and 'Vairo' a strong vigor cultivar $[15,26]$. For the 'Marinada' trial, trees were planted in a randomized complete block design, with twelve single-tree replications. Rootstocks included in this trial were Cadaman ${ }^{\circledR}$, Garnem ${ }^{\circledR}$, INRA GF-677, IRTA 1 and IRTA 2, Ishtara ${ }^{\circledR}$, Adesoto, Rootpac ${ }^{\circledR} 20$, Rootpac ${ }^{\circledR} 40$, and Rootpac ${ }^{\circledR}$ R [27]. For the 'Vairo' trial, trees were planted in a randomized complete block design, with six singletree replications. With the exception of Cadaman ${ }^{\circledR}$ and Garnem ${ }^{\circledR}$, the same Rootstocks as before were included in this trial [27]. All trees were trained to an open vase system, with a tree spacing of $5 \mathrm{~m} \times 4.5 \mathrm{~m}$. 
The P3 orchard was planted with dormant budded trees in 2010, again with 'Marinada' and 'Vairo' as the scion cultivars, both grafted onto IRTA 2 rootstock [27,28]. In this plot, trees were managed according to three different pruning strategies: (i) no pruning, by leaving all natural main branches and then pruning cuts were only made when branches appeared to be dying or dead; (ii) long pruning, choosing 4-6 branches as scaffolds and after that no more cuts were done on these branches and/or secondary and tertiary branches; and (iii) short pruning, three main branches were chosen for primary scaffolds, and then these branches and secondary and tertiary branches were headed back to 1/3 of their length during the dormant season. The trial was designed as a randomized complete block experiment with a split plot and eight single-tree replications. Cultivar was the main plot with each main plot consisting of three $50 \mathrm{~m}$ long rows. Pruning management was in sub-plots, which each consisted of a $50 \mathrm{~m}$ long row. Trees were trained to an open vase system, with a tree spacing of $6 \mathrm{~m} \times 6 \mathrm{~m}$.

For all the orchards, the soil was a clay-loam type, with good water holding capacity, well drained, and fertile with about $2 \%$ organic matter content. Trees were drip-irrigated (climate is semi-arid Mediterranean, with a mean annual rainfall of $350 \mathrm{~mm}$ ) on a daily basis, calculating water requirements through a water balance method for replacing crop evapotranspiration $\left(\mathrm{ET}_{\mathcal{c}}\right)$ as follows: $\mathrm{ET}_{\mathcal{C}}=\left(\mathrm{ET}_{o} \times \mathrm{Kc}\right)$-effective rainfall. The $\mathrm{ET}_{o}$ was collected from the public network of weather stations closest to the study site [29], which uses the Penman-Monteith method [30] to calculate it. The total amount of water applied throughout the growing season (from April to October) ranged from $600 \mathrm{~mm}$ to $650 \mathrm{~mm}$, depending on the trial and year. Plots were managed within IPM management according to industry standards, with the exception of P1 where no fungicides were applied. Beehives were placed every year in all the orchards, at a rate of 5 hives/ha from budbreak to petal fall, circa of one month.

\subsection{Horticultural Assessments $\mathcal{E}$ Data Analysis}

All the assessments were visually made on fully mature trees. Phenological stage was also recorded every year on a biweekly-basis from bud break (B) to fruit growth (I) [31]. Fruit drop was assessed by noting the number and development stage of buds, flowers, and fruitlets located on 1-2-year-old shoots every 10-15 days, from pink bud to harvest ( 40-60 buds/shoot) (Table 1$)$. Observations were made on one branch per tree and 2 trees/rep for P1 (8 trees/cultivar), two branches per tree and 1 tree/rep for P2 (four trees for rootstock), and two branches per tree and 2 trees/rep for P3 (8 trees/pruning treatment). Data was recorded over three seasons (2015-2017) for P1 (cultivars), and over two years (2017-2018) for P2 (rootstocks) and P3 (pruning management). For this study, 17,009 buds were assessed in P1; 14,828 buds in P2; and 7,563 in P3; totaling 39,400 assessed buds for the whole study (Table 1). Fruit drop was calculated as the number of either buds, flowers, or fruits at the sampling day in relation to the initial number of buds (cumulative $\%$ fruit drop) or to the previous sampling day (fruit drop rate, $\%$ fruit drop from previous observation). Data for each treatment, plot, and year was then normalized in relation to days from full bloom (DFFB). For P2 and P3, tree height and tree width in the row and in the alley were measured each year. Tree volume $\left(4 / 3 \pi r^{3}\right)$ was then calculated. Every year at harvest, trees from P2 and P3 were shaken mechanically by commercial equipment. The in-shell nuts were then harvested with an inverted-umbrella and hulls removed using a self-moving huller. Once the in-shell nuts were dehulled, their fresh weight was measured, and the gross yield calculated. A $1 \mathrm{~kg}$ in-shell nut sample was collected from each replicate and naturally dried for about three-four weeks (until reaching 6\% of kernel moisture). Dry weight was determined, and then one sample of 100 in-shell nuts per $1 \mathrm{~kg}$ was collected to determine shell and kernel dry weights, and shelling percentage (kernel weight/in-shell weight $\times 100)$. Kernel yield was calculated by multiplying in-shell nut yield $(\mathrm{kg} / \mathrm{tree})$ for shelling percentage (kernel weight/in-shell weight). Production in kernel yield per tree was normalized in relation to tree volume. 
Table 1. Number of buds assessed per year (2015-2018) to calculate fruit drop rate for each cultivar, rootstock, and pruning type in each of the three plots at Les Borges Blanques, Spain.

\begin{tabular}{|c|c|c|c|c|c|c|c|c|}
\hline \multirow{2}{*}{ Plot \# } & \multirow{2}{*}{ Cultivar } & \multirow{2}{*}{ Rootstock } & \multirow{2}{*}{ Pruning Type } & \multicolumn{4}{|c|}{ Number of Buds Sampled } & \multirow{2}{*}{$\sum$ by Row } \\
\hline & & & & 2015 & 2016 & 2017 & 2018 & \\
\hline \multirow{21}{*}{1} & Antoñeta & INRA GF-677 & & 173 & 257 & 178 & & 608 \\
\hline & Belona & & & 278 & 369 & 235 & & 882 \\
\hline & Constantí & & & 226 & 380 & 242 & & 848 \\
\hline & Ferragnès & & & 183 & 405 & 257 & & 845 \\
\hline & Francolí & & & 225 & 357 & 318 & & 900 \\
\hline & Glorieta & & & 259 & 323 & 156 & & 738 \\
\hline & Guara & & & 183 & 292 & 229 & & 704 \\
\hline & Lauranne & & & 350 & 298 & 326 & & 974 \\
\hline & Largueta & & & 236 & 257 & 257 & & 750 \\
\hline & Marcona & & & 138 & 153 & 260 & & 551 \\
\hline & Mardía & & & 162 & 242 & 218 & & 622 \\
\hline & Marinada & & & 191 & 334 & 304 & & 829 \\
\hline & Marta & & & 278 & 243 & 267 & & 788 \\
\hline & Masbovera & & & 354 & 412 & 163 & & 929 \\
\hline & Penta & & & 280 & 247 & 264 & & 791 \\
\hline & Soleta & & & 404 & 351 & 437 & & 1192 \\
\hline & Tardona & & & 247 & 212 & 390 & & 849 \\
\hline & Tarraco & & & 430 & 617 & 543 & & 1590 \\
\hline & Tuono & & & 198 & 255 & 184 & & 637 \\
\hline & Vairo & & & 300 & 402 & 280 & & 982 \\
\hline & & Total Plot 1 & & 5095 & 6406 & 5508 & & 17,009 \\
\hline \multirow{21}{*}{2} & Marinada & & & & & 3376 & 5303 & 8679 \\
\hline & & Adesoto & & & & 332 & 548 & 880 \\
\hline & & Cadaman & & & & 410 & 531 & 941 \\
\hline & & Garnem & & & & 291 & 465 & 756 \\
\hline & & INRA GF-677 & & & & 302 & 554 & 856 \\
\hline & & IRTA 1 & & & & 421 & 542 & 963 \\
\hline & & IRTA 2 & & & & 294 & 522 & 816 \\
\hline & & Ishtara & & & & 295 & 573 & 868 \\
\hline & & Rootpac 20 & & & & 318 & 452 & 770 \\
\hline & & Rootpac 40 & & & & 358 & 569 & 927 \\
\hline & & Rootpac R & & & & 355 & 547 & 902 \\
\hline & Vairo & & & & & 2521 & 3628 & 6149 \\
\hline & & Adesoto & & & & 374 & 495 & 869 \\
\hline & & INRA GF-677 & & & & 268 & 412 & 680 \\
\hline & & IRTA 1 & & & & 336 & 408 & 744 \\
\hline & & IRTA 2 & & & & 280 & 410 & 690 \\
\hline & & Ishtara & & & & 301 & 554 & 855 \\
\hline & & Rootpac 20 & & & & 317 & 431 & 748 \\
\hline & & Rootpac 40 & & & & 345 & 419 & 764 \\
\hline & & Rootpac R & & & & 300 & 499 & 799 \\
\hline & & Total & t 2 & & & 5897 & 8931 & 14,828 \\
\hline \multirow{9}{*}{3} & \multicolumn{3}{|c|}{ IRTA 2} & & & 1947 & 2125 & 4072 \\
\hline & & & No pruning & & & 604 & 827 & 1431 \\
\hline & & & Long & & & 765 & 572 & 1337 \\
\hline & & & Short & & & 578 & 726 & 1304 \\
\hline & Vairo & IRTA 2 & & & & 2086 & 1405 & 3491 \\
\hline & & & No pruning & & & 633 & 573 & 1206 \\
\hline & & & Long & & & 774 & 431 & 1205 \\
\hline & & & Short & & & 679 & 401 & 1080 \\
\hline & & Total & t 3 & & & 4033 & 3530 & 7563 \\
\hline
\end{tabular}


Specialized modeling for cumulative fruit drop and DFFB from bud break and up to 180 days after full bloom were performed for each cultivar (P1), rootstock (P2) and pruning management (P3) in order to identify the curve with the best fit. Models were selected according to the lowest Corrected Akaike's Information Criteria $\left(\mathrm{AIC}_{\mathrm{c}}\right)$. Analysis of Means (ANOM) was used to compare parameters for each treatment. Data for all years were pooled together for the analysis. Four two-way hierarchical cluster analyses using the Ward method were built in order to classify the pruning type and rootstocks for both cultivars 'Marinada' and 'Vairo' based on cumulative percentage fruit drop, inflection point, and kernel yield $\left(\mathrm{kg} /\right.$ tree) normalized by tree volume $\left(\mathrm{m}^{3}\right)$. Data were analyzed using the JMP statistical software package (Version 14; SAS Institute Inc., Cary, North Carolina).

\section{Results}

\subsection{General Fruit Drop Patterns}

There were up to four periods of almond drop. The first fruit drop peaked at $20 \mathrm{DFFB}$, the second one at 100 DFFB, a third one at 120-140 DFFB, and the last one at 160-180 DFFB (Figure 1A). The first fruit drop, which had the peak around 20 days after full bloom, started a few days before bloom through 60-80 days after bloom, and was the main fruit drop period (Figure 1A). At that period, fruit drop in relation to the previous sampling day mainly ranged from $10-50 \%$, but in some cases reached up to $70 \%$. The remaining three later fruit drops had a maximum of $30 \%$ fruit drop in relation to the previous sampling day. When looking at the cumulative almond drop, once fruit set reached 50 to 60 days after full bloom, fruit drop tended to stabilize and, in general, no more significant fruit drops were observed. Cumulative fruit drop ranged from $50 \%$ to $90 \%$ (Figure 1B).
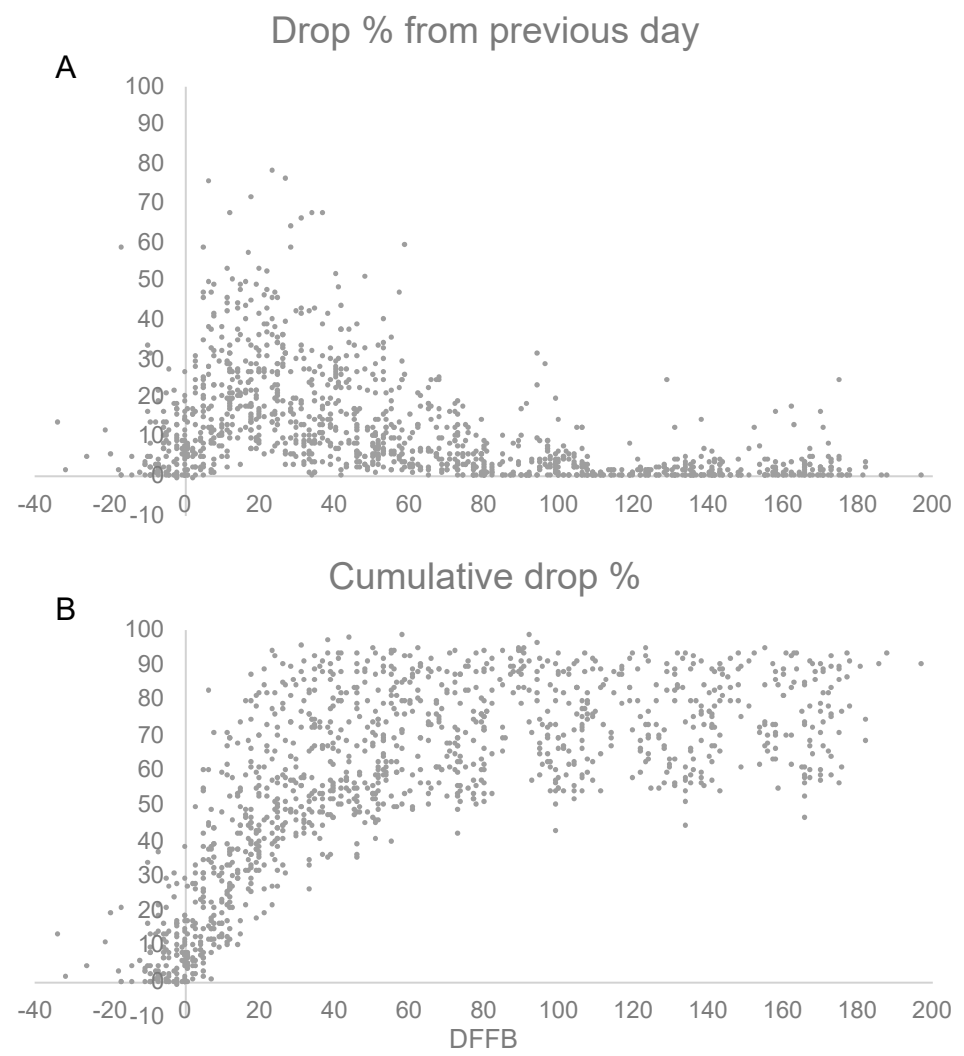

Figure 1. Fruit drop percentage from previous sampling day (A) and cumulative fruit drop percentage of almond crop along days from full bloom (DFFB) (B) at Les Borges Blanques, Spain. Each dot represents the average of trees during 2015-2018. Data belongs to twenty different cultivars (P1), two almond cultivars grafted onto eight to ten rootstocks (P2), and two cultivars with three different pruning types (P3). 


\subsection{Fruit Drop Patterns by Cultivar}

Overall, in all cultivars the main fruit drop coincided with the first period (20-60 DFFB) (Figure 2). In addition, 'Antoñeta', 'Belona', 'Ferragnès', and 'Tarraco' cultivars had a further small fruit drop around $160 \mathrm{DFFB}$, 'Guara' and 'Lauranne' had one at $180 \mathrm{DFFB}$, and the last 'Glorieta' fruit drop ranged from 120-140 DFFB.

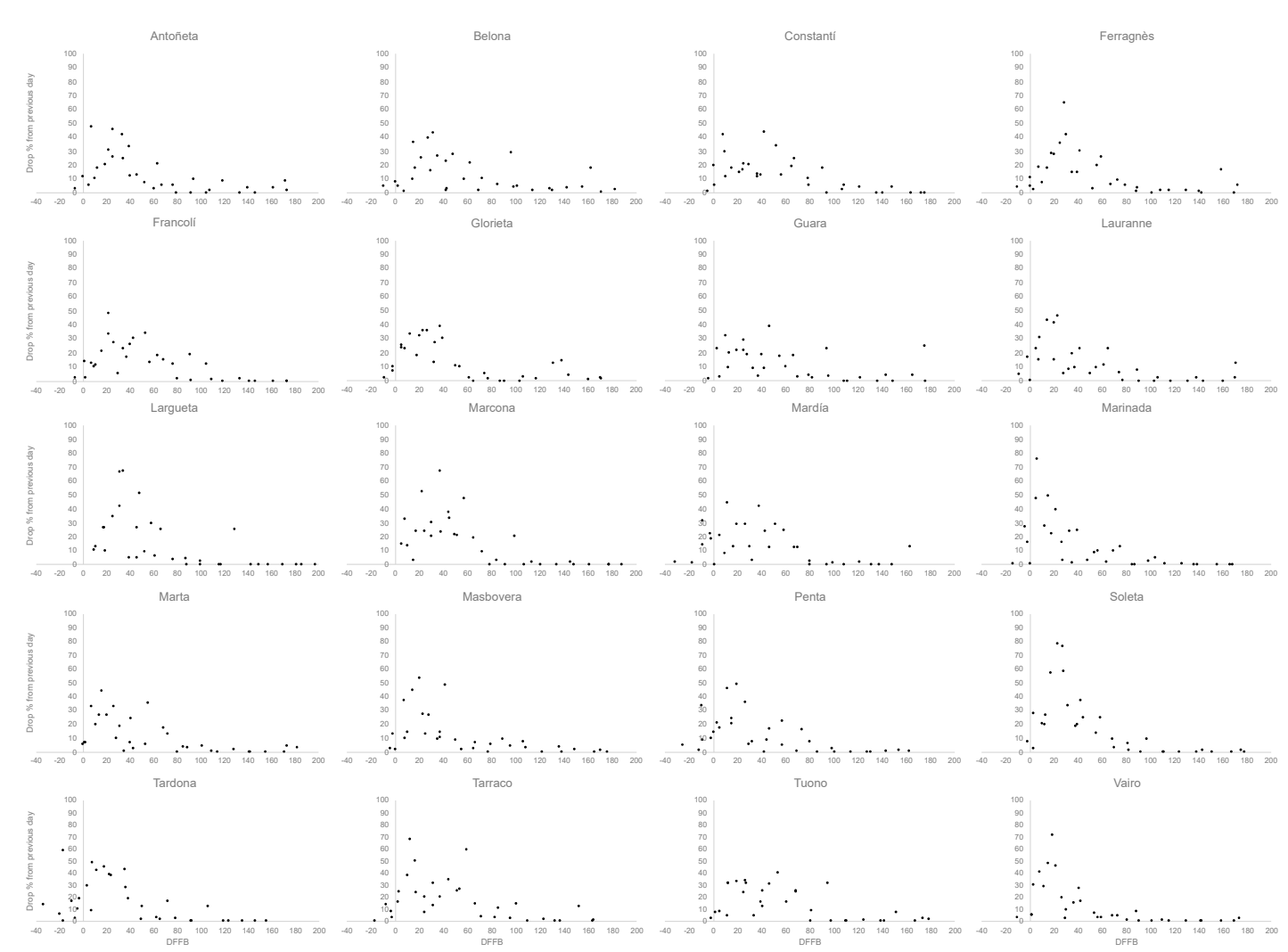

Figure 2. Fruit drop percentage from previous day for twenty different almond cultivars along days from full bloom (DFFB) at Les Borges Blanques, Spain (P1). Each dot represents the average of eight trees and one branch/tree. Data was recorded during 2015-2017.

Cumulative fruit drop for all the cultivars had a good fit under a logistic threeparameter model $\left(R^{2}=0.87\right.$, data not shown). Growth rate, inflection point, and asymptote were highly significant for all the cultivars $(<0.0001)$, with the exception of 'Penta' and 'Tardona', which had no significant inflection point (data not shown). While there were no significant differences among cultivars regarding the growth rate, 'Marinada', 'Marta', 'Masbovera', 'Soleta', and 'Vairo' tended to have higher fruit drop rates than the rest of the cultivars (Figure 3). There were significant differences among cultivars regarding the time in which the fruit drop began to decrease (inflection point). As a result, 'Belona', 'Francoli', 'Largueta', and 'Marcona' were the varieties which had steep fruit drops for a longer period of time (Figure 3). A second group comprised 'Antoñeta', 'Constantí', 'Ferragnès', 'Glorieta', 'Guara', 'Lauranne', 'Mardía', 'Marta', 'Masbovera', 'Soleta', 'Tarraco', and 'Tuono'. A third group comprised 'Marinada', 'Penta', 'Tardona', and 'Vairo', which were the varieties where cumulative fruit drop started to deaccelerate earlier (lower inflection point value). There were significant differences regarding the maximum cumulative fruit drop depending on the cultivar (asymptote). 'Largueta', 'Marcona', 'Soleta', and 'Tarraco' were the cultivars that had higher cumulative fruit drop, with values around $90 \%$ (Figure 3). A second group comprised 'Antoñeta', 'Constantî', 'Ferragnès', 'Francolí, 'Glorieta', 'Guara', 'Lauranne', 'Mardía', 'Marinada', 'Tardona', 'Tuono', and 'Vairo' with values that ranged from 72-87\%. 
A third group comprised 'Belona', 'Marta', 'Masbovera', and 'Penta', which had the lowest maximum cumulative fruit drop $(62-72 \%)$.

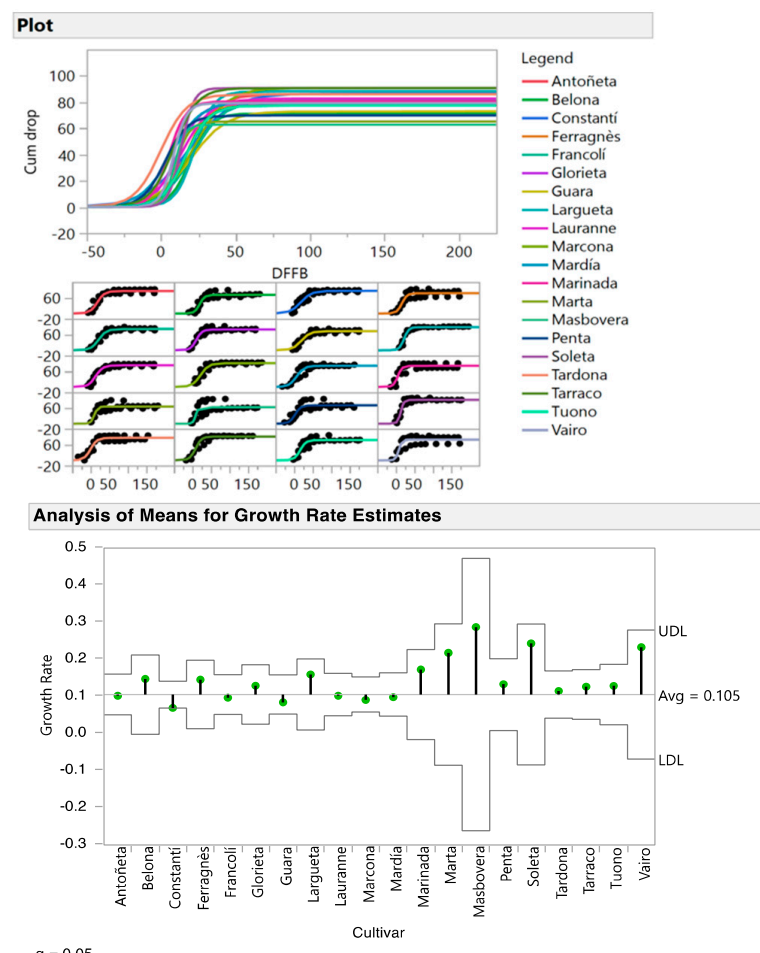

$a=0.05$

Analysis of Means for Inflection Point Estimates

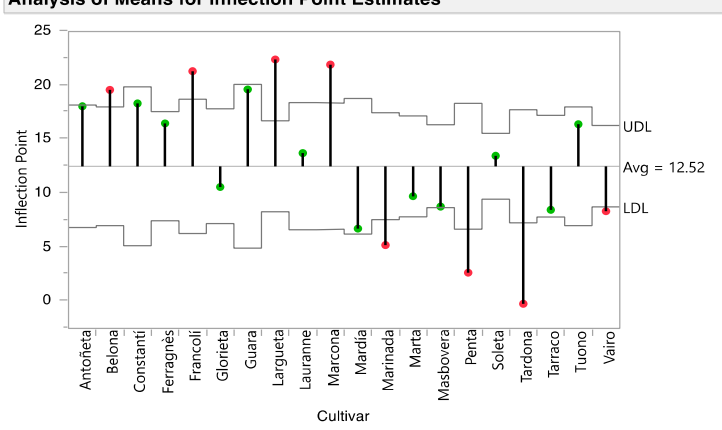

$a=0.05$

Analysis of Means for Asymptote Estimates

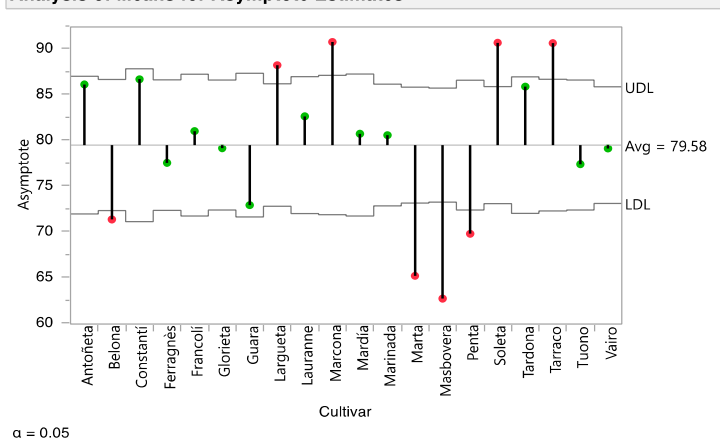

Figure 3. Fitted curves and parameter comparison for the logistic three-parameter models fitted to describe the relationship from bud break until 180 days after full bloom between cumulative fruit drop (\%) and days from full bloom (DFFB) for 'Antoñeta', 'Belona', 'Constantí', 'Ferragnès', 'Francoli', 'Glorieta', 'Guara', 'Lauranne', 'Largueta', 'Marcona', 'Mardía', 'Marinada', 'Marta', 'Masbovera', 'Penta', 'Soleta', 'Tardona', 'Tarraco', 'Tuono', and 'Vairo' almond cultivars at Les Borges Blanques, Spain (P1). Data were recorded during 2015-2017. 


\subsection{Fruit Drop Patterns by Rootstock}

For 'Marinada' and 'Vairo' logistic three-parameter models for cumulative fruit drop with days from bud break until 180 days after full bloom had a good fit $\left(R^{2}=0.86\right.$ and $\mathrm{R}^{2}=0.88$, respectively; data not shown). Growth rate, inflection point, and asymptote were highly significant for all the rootstocks with either 'Marinada' or 'Vairo' $(<0.0001)$ (data not shown). There were no significant differences among rootstocks for 'Marinada' regarding the growth rate and inflection point (Figure 4). Nevertheless, there were different patterns regarding the inflection point, suggesting that Ishtara ${ }^{\circledR}$ tended to stop the fruit drop earlier than Garnem ${ }^{\circledR}$, Rootpac ${ }^{\circledR} 20$, and Rootpac ${ }^{\circledR} 40$ (Figure 4). In addition, even though there were no significant differences, Ishtara ${ }^{\circledR}$ seemed to have higher fruit drop rate than for instance Garnem ${ }^{\circledR}$, INRA GF-677, and Rootpac ${ }^{\circledR} 40$. In terms of maximum cumulative fruit drop, Rootpac ${ }^{\circledR} R$ had significantly less fruit drop than when 'Marinada' was grafted onto the rest of the rootstocks (Figure 4).

For 'Vairo', there were no significant differences among rootstocks regarding the growth rate or inflection point (Figure 5). However, for this cultivar INRA GF-677 seemed to have higher fruit drop rate than for instance Adesoto, which had the lowest. On the other hand, INRA GF-677 seemed to stop the fruit drop earlier than for instance when 'Vairo' was grafted onto IRTA 2 or Rootpac ${ }^{\circledR} 20$ (Figure 5). In terms of maximum cumulative fruit drop, IRTA $1(55 \%)$ had significantly less cumulative drop than the rest of the rootstocks $(\sim 64 \%)$.

\subsection{Fruit Drop Patterns by Pruning Type}

There was a good fit $\left(R^{2}=0.93\right)$ when using logistic three-parameter models to describe the relationships between cumulative fruit drop and days from bud break until 180 days after full bloom for all the different pruning types and cultivars (data not shown). Growth rate, inflection point, and asymptote were highly significant for all the pruning types with either 'Marinada' or 'Vairo' (<0.0001) (data not shown). There were not significant differences regarding the fruit drop rate among cultivars and pruning types (Figure 6). However, there was a clear trend where short pruning had lower fruit drop rate than either long pruning or no pruning for both cultivars (Figure 6). 'Marinada' decelerated the cumulative fruit drop significantly earlier than 'Vairo'. For 'Marinada' this was especially significant when no pruning was done, whereas for 'Vairo' no pruning and short pruning fruit drop began to decrease significantly later than when long pruning was done (Figure 6). Overall, 'Vairo' had higher fruit drop levels, with the exception when short pruning was done, which was lower than the average. For 'Marinada', both long pruning and short pruning had significantly lower fruit drop than when no pruning was done.

\subsection{Fruit Drop Patterns and Yield}

Taking into account the cumulative fruit drop pattern-the moment that the fruit drop rate began to deaccelerate (inflection point) — and the kernel yield, rootstocks were clustered into five different groups, depending on the cultivar (Figure 7). For 'Marinada', the first group included Adesoto, INRA GF-677, IRTA 1, and IRTA 2. This group had medium values for all three parameters (inflection point, normalized kernel yield, and cumulative fruit drop). A second group comprised Garnem ${ }^{\circledR}$ and Rootpac ${ }^{\circledR} 40$. This group had higher inflection point values than the first group, suggesting that with similar yield and cumulative fruit drop, their fruit drop period lasted longer, reaching the deacceleration point later on time (20 or $18 \mathrm{DFFB}$, respectively). Rootpac ${ }^{\circledR} 20$ was clustered alone since that was the rootstock that had the highest normalized kernel yield $\left(0.2 \mathrm{~kg} / \mathrm{m}^{3}\right)$ and among the ones with the highest inflection point (19 DFFB). The fourth group comprised Cadaman ${ }^{\circledR}$ and Ishtara ${ }^{\circledR}$, which were the rootstocks where the fruit drop began to decrease earlier (8-10 DFFB), but still had high cumulative fruit drop (59-67\%). The last group only comprised Rootpac ${ }^{\circledR} \mathrm{R}$, which had the lowest values on normalized kernel yield $\left(0.16 \mathrm{~kg} / \mathrm{m}^{3}\right)$ and cumulative fruit drop (52\%), and was among the lowest regarding inflection point (12 DFFB). 

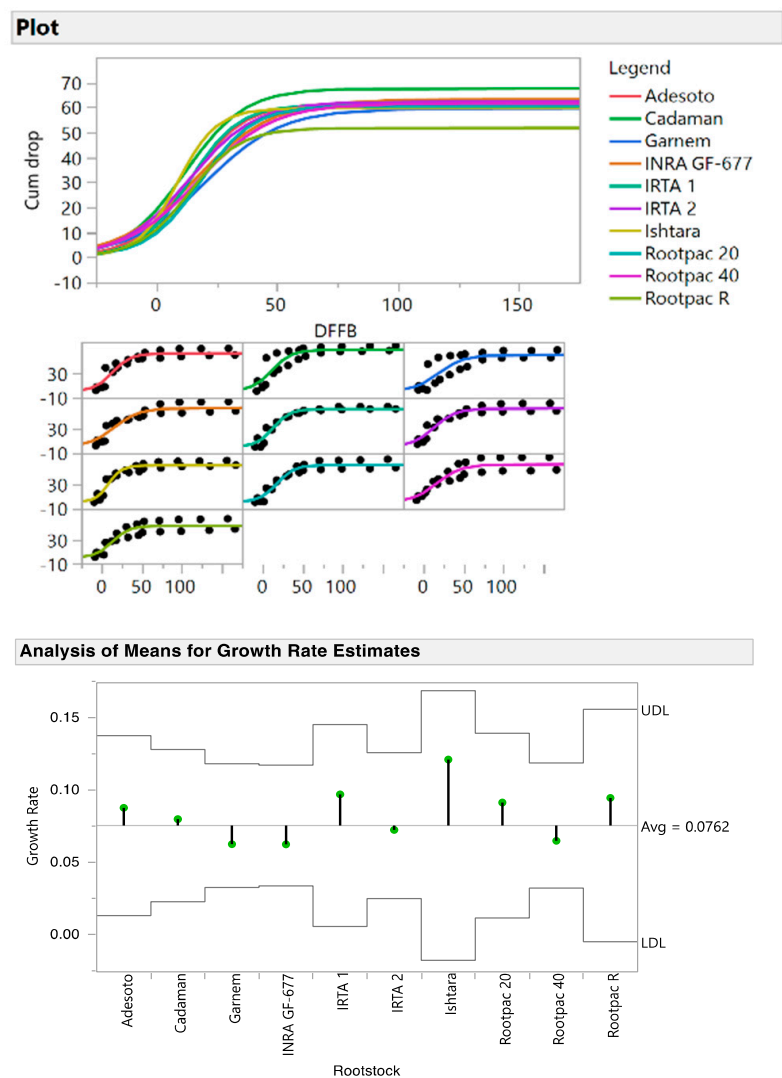

$a=0.05$

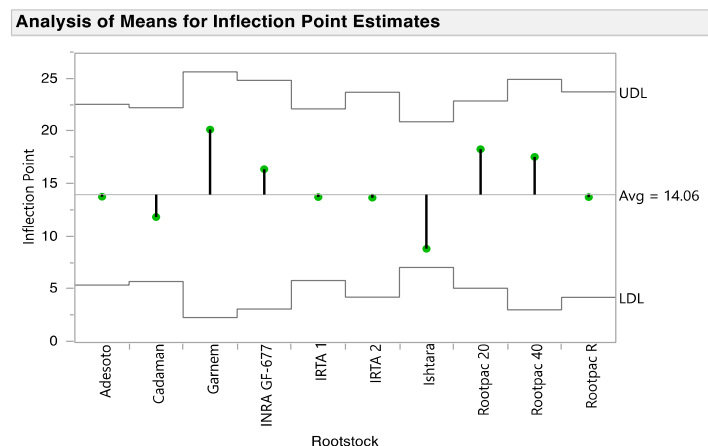

$a=0.05$

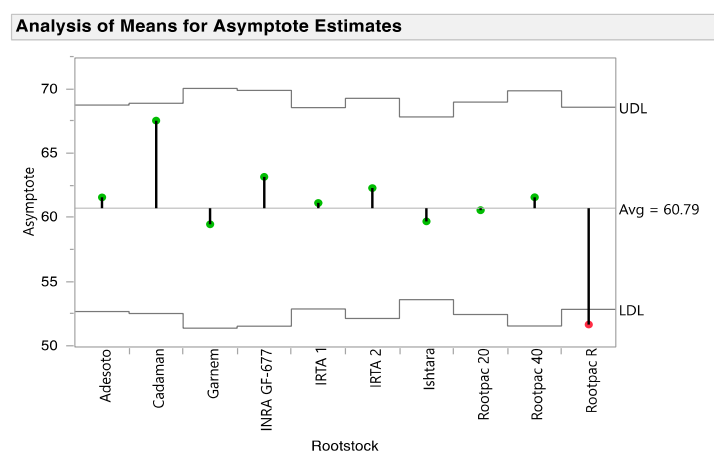

$a=0.05$

Figure 4. Fitted curves and parameter comparison for the logistic three-parameter models fitted to describe the relationship from bud break until 180 days after full bloom between cumulative fruit drop (\%) and days from full bloom (DFFB) for 'Marinada' grafted onto Adesoto, Cadaman ${ }^{\circledR}$, Garnem $^{\circledR}$, INRA GF-677, IRTA 1, IRTA 2, Ishtara ${ }^{\circledR}$, $\operatorname{Rootpac}^{\circledR}$ 20, Rootpac $^{\circledR} 40$, and Rootpac $^{\circledR}$ R rootstocks at Les Borges Blanques, Spain (P2). Data were recorded during 2017-2018. 

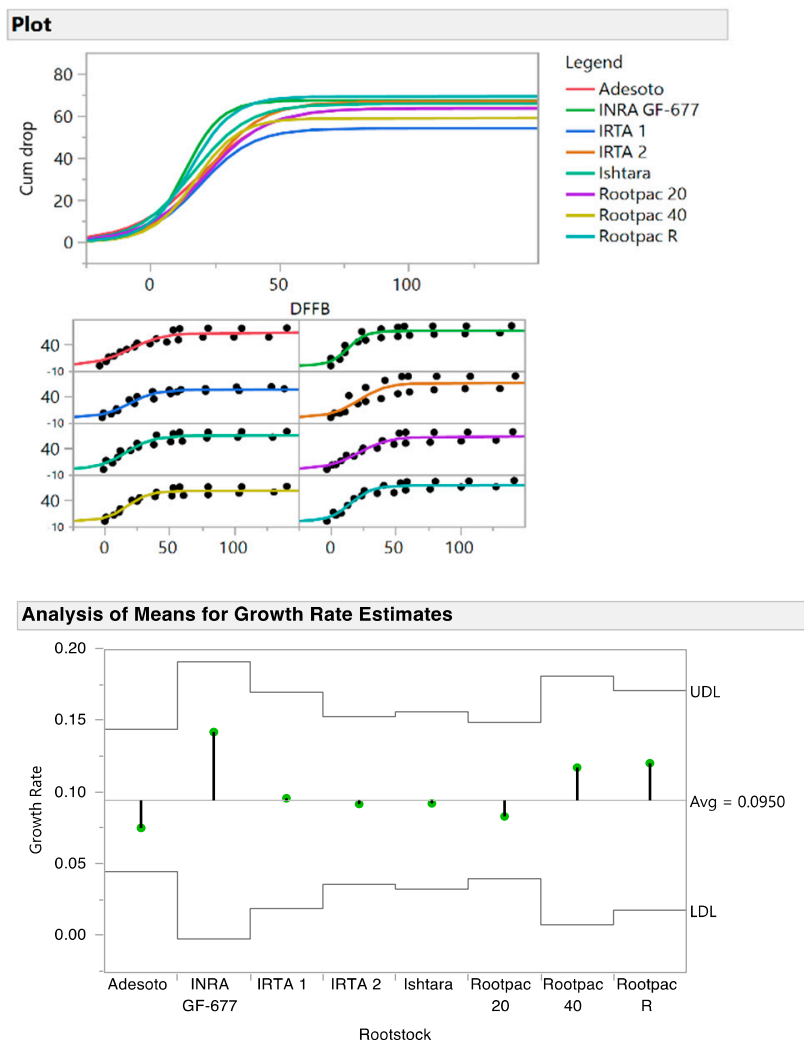

$a=0.05$

Rootstock

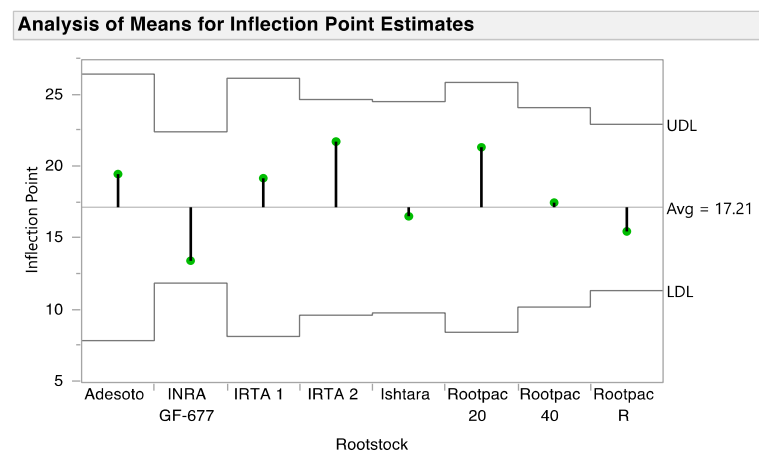

$a=0.05$
Analysis of Means for Asymptote Estimates

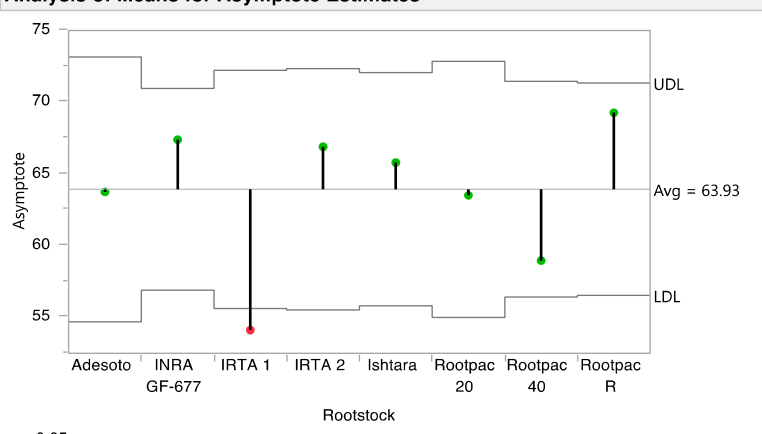

$a=0.05$

Figure 5. Fitted curves and parameter comparison for the logistic three-parameter models fitted to describe the relationship from bud break until 180 days after full bloom between cumulative fruit drop (\%) and days from full bloom (DFFB) for 'Vairo' grafted onto Adesoto, INRA GF-677, IRTA 1, IRTA 2, Ishtara ${ }^{\circledR}$, Rootpac ${ }^{\circledR} 20$, Rootpac ${ }^{\circledR} 40$, and Rootpac ${ }^{\circledR} R$ rootstocks at Les Borges Blanques, Spain (P2). Data were recorded during 2017-2018. 

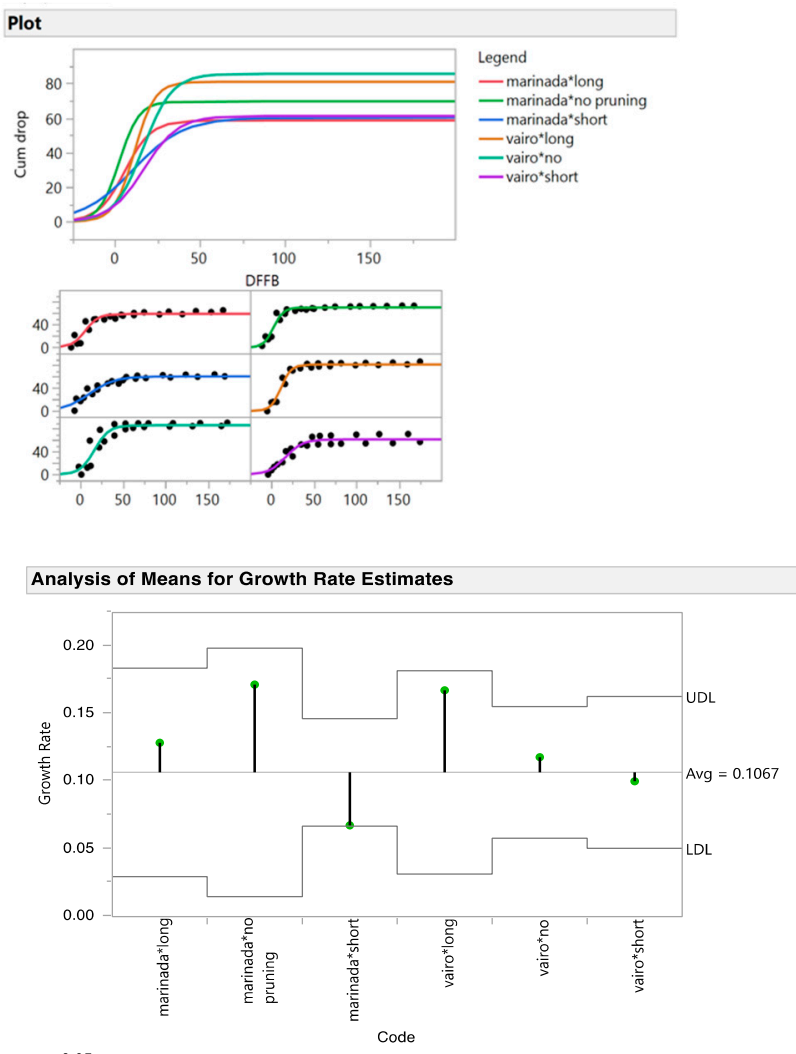

$a=0.0$

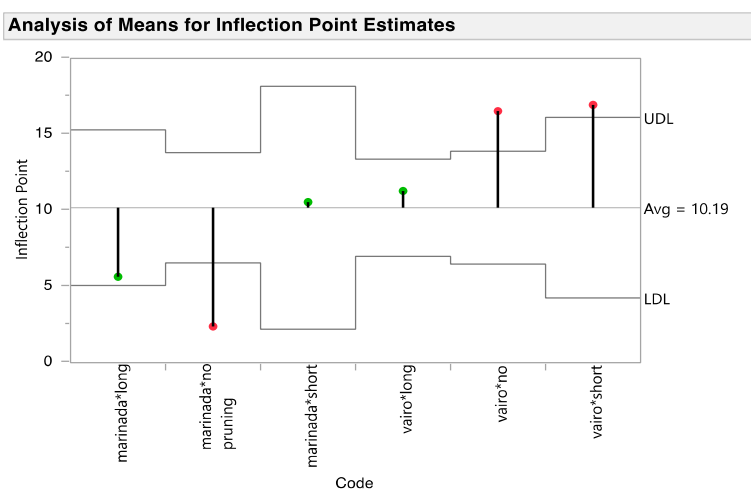

$a=0.05$

Analysis of Means for Asymptote Estimates

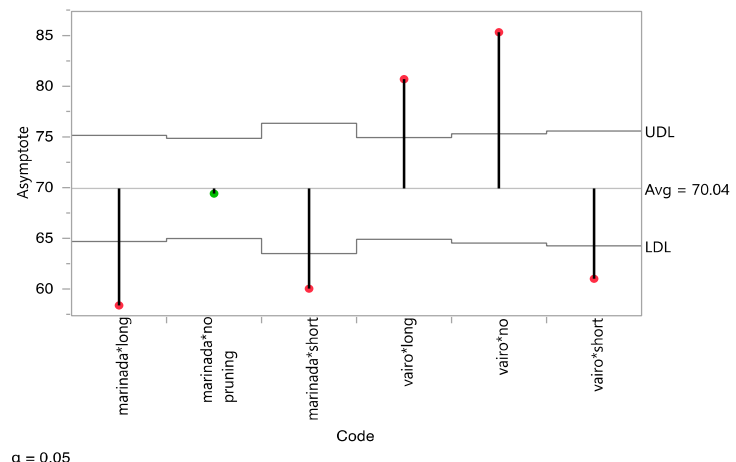

Figure 6. Logistic three-parameter model and parameter comparison to describe the relationship from bud break until 180 days after full bloom between cumulative fruit drop (\%) and days from full bloom (DFFB) for 'Marinada' under three different pruning types at Les Borges Blanques, Spain (P3). Data were recorded during 2017-2018. 

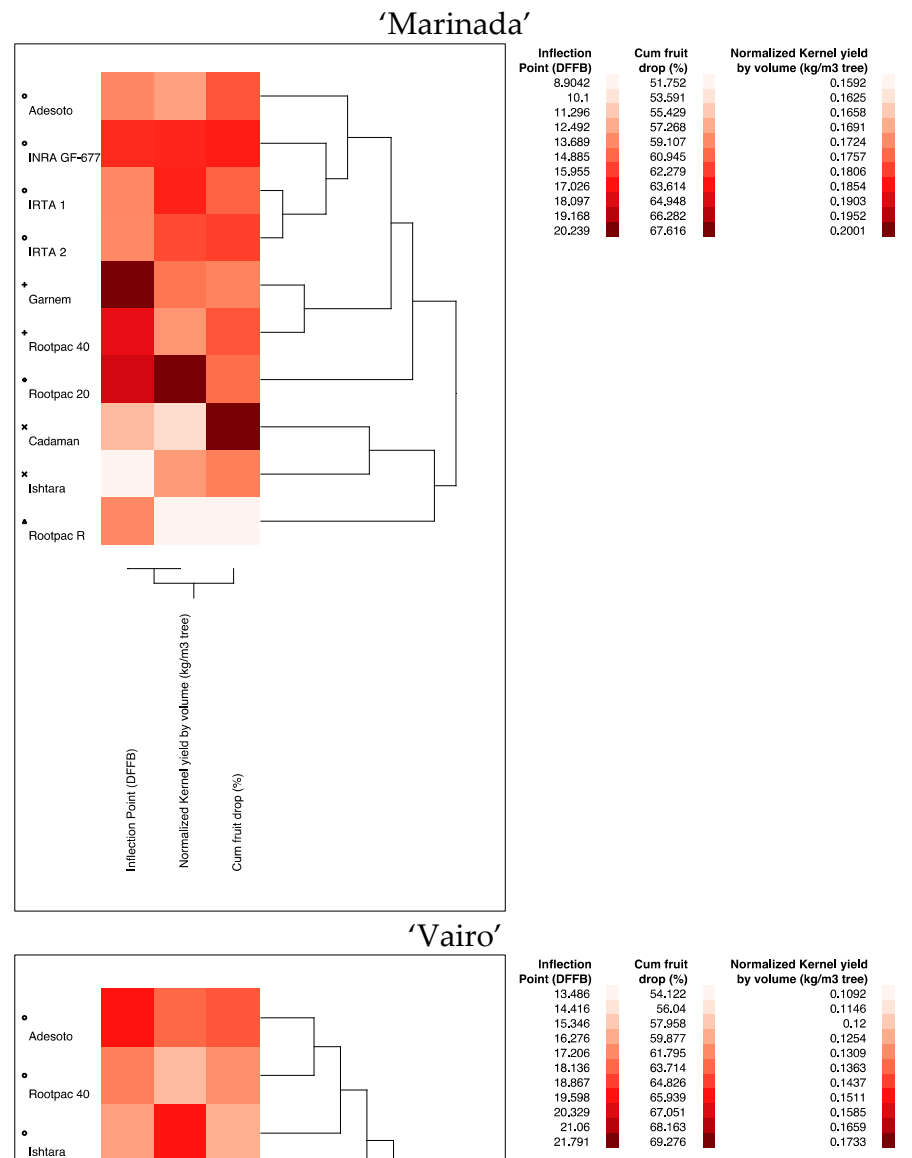

Figure 7. Clustering of 'Marinada' and 'Vairo' cultivars grafted onto Adesoto, Cadaman ${ }^{\circledR}$, Garnem ${ }^{\circledR}$ INRA GF-677, IRTA 1, IRTA 2, Ishtara ${ }^{\circledR}$, $\operatorname{Rootpac}^{\circledR} 20$, Rootpac ${ }^{\circledR} 40$, and Rootpac ${ }^{\circledR} \mathrm{R}$ rootstocks based on cumulative fruit drop (\%), inflection point (days from full bloom that fruit drop began to deaccelerate), and kernel yield ( $\mathrm{kg} /$ tree) normalized by tree volume $\left(\mathrm{m}^{3}\right)$ at Les Borges Blanques, Spain (P2). Data were recorded during 2017-2018.

For 'Vairo', Adesoto, Rootpac ${ }^{\circledR} 40$, and Ishtara ${ }^{\circledR}$ were clustered together. This first group comprised the rootstocks that had medium average values on all three parameters (Figure 7). Rootpac ${ }^{\circledR} 20$ was clustered alone, since it was one of the rootstocks with higher inflection point (21 DFFB) and the lowest normalized kernel yield $\left(0.11 \mathrm{~kg} / \mathrm{m}^{3}\right)$. The third group comprised IRTA 1, which had high inflection point (19 DFFB), the lowest cumulative fruit drop $(54 \%)$, and low normalized kernel yield $\left(0.11 \mathrm{~kg} / \mathrm{m}^{3}\right)$. The fourth 
group comprised INRA GF-677, and Rootpac ${ }^{\circledR}$ R. This group had high normalized kernel yields $\left(0.15 \mathrm{~kg} / \mathrm{m}^{3}\right)$, the highest cumulative fruit drop (68-69\%), and the lowest inflection points (13-14 DFFB). IRTA 2 was clustered alone. This rootstock had the highest normalized kernel yield $(0.17 \mathrm{~kg} / \mathrm{m} 3)$ and inflection point $(21 \mathrm{DFFB})$, and one of the highest cumulative fruit drop $(67 \%)$.

When looking at the effect of pruning type, for 'Marinada' long pruning had the highest normalized kernel yield $\left(0.27 \mathrm{~kg} / \mathrm{m}^{3}\right)$ and the lowest cumulative fruit drop $(59 \%)$ (Figure 8). On the other hand, short pruning had the lowest kernel yield $\left(0.25 \mathrm{~kg} / \mathrm{m}^{3}\right)$, medium fruit drop $(60 \%)$, and the highest inflection point (11 DFFB). No pruning had the shortest period of time before cumulative drop deacceleration started (2 DFFB), yet it reached the highest cumulative fruit drop $(70 \%)$ and medium kernel yield $\left(0.25 \mathrm{~kg} / \mathrm{m}^{3}\right)$.

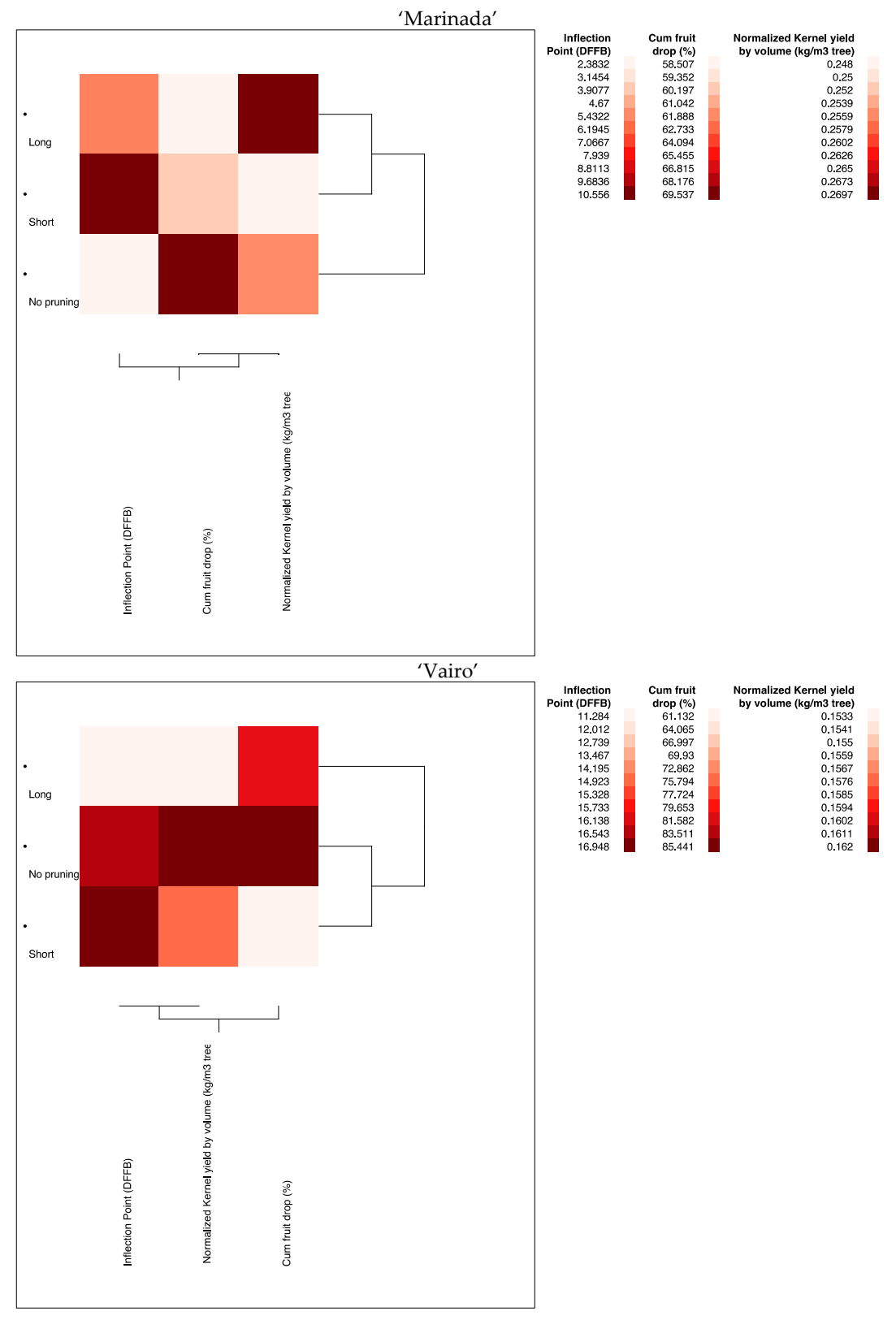

Figure 8. Clustering of 'Marinada' and 'Vairo' according to their pruning type (no pruning, long pruning, and short pruning) based on percentage fruit drop (\%), inflection point (days from full bloom that fruit drop began to deaccelerate), and kernel yield ( $\mathrm{kg} /$ tree) normalized by tree volume $\left(\mathrm{m}^{3}\right)$ at Les Borges Blanques, Spain (P3). Data were recorded during 2017-2018. 
For 'Vairo', no pruning had the highest values of kernel yield $\left(0.16 \mathrm{~kg} / \mathrm{m}^{3}\right)$ and cumulative fruit drop (85\%), whereas the inflection point was the second highest among the three (16 DFFB) (Figure 8). Mid-range yield values were attained when short pruning was performed, with the lowest values of cumulative fruit drop (61\%). Long pruning had the lowest kernel yield $\left(0.15 \mathrm{~kg} / \mathrm{m}^{3}\right)$ and inflection point (11 DFFB), with medium value regarding the cumulative fruit drop $(80 \%)$.

For 'Marinada' long and short pruning were more similar to each other than to no pruning (Figure 8). On the other hand, for 'Vairo', no pruning and short pruning had more similarities than long pruning.

\section{Discussion}

Fruit drop patterns were mainly the result of different drops of buds, flowers, and fruits at diverse stages of the biological cycle. There were up to four fruit drops during the season, the main one occurring from 20-60 days after full bloom. Subsequent fruit drops were at 100 DFFB, at 120-140 DFFB, and the last one at 160-180 DFFB, even though these subsequent fruit drops were significantly less apparent. The organ that dropped could be assigned according to the time it happened. For instance, from 40 days before bloom until bloom ( -40 to 0 DFFB) was bud drop. Since average bloom length in our conditions was about 16 days [27], we assigned flower drop as occurring from 0 to 16 DFFB. After that, all drops were counted as fruit drops. As a result, and in general terms for all the different cultivars, about half of the cumulative drop comprised buds and flowers, and the remaining percentage were fruit drops, which occurred from 20 days after full bloom onwards.

In previous studies, three periods of almond fruit drop have been described [14], however, all these three periods of fruit drop may not coincide during the same season. In that study, which was carried out on the 'Nonpareil' cultivar, cumulative fruit drop reached up to $60-70 \%$ within 55 days after full bloom. This coincides with the results of our study, where cumulative fruit drop for all cultivars happened within -30 to 60 DFFB. Nonetheless, different cumulative fruit drops were observed in our study depending on the cultivar. The highest cumulative fruit drops ( $90 \%)$ were for 'Largueta' 'Marcona', 'Soleta', and 'Tarraco'; whereas the lowest $(<70 \%)$ were for 'Marta', 'Masbovera', and 'Penta'. Average fruit drop for all the cultivars was $79.6 \%$. In previous studies on different cultivars, average fruit drop has been reported to fluctuate between $60-80 \%$ [8-10]. However, to our knowledge, there are no reports on timing about when they occur for the cultivars we used in our study. In addition, different trends regarding fruit drop rates were also observed depending on the cultivar. For instance, 'Marta', 'Masbovera', 'Soleta', and 'Vairo' had the highest relative rates of fruit drop, whereas 'Constantí' and 'Guara' had the lowest. Even though there were no significant differences, the trends we observed in the means for growth rate estimates suggest different plasticity in terms of cultivar management, since cultivars with the steepest slope have less margin for manipulation. In addition, depending on the cultivar, fruit drop may deaccelerate earlier in the season, right at bloom or petal fall, or keep dropping for a long period of time (high inflection point). For instance, we observed that late- and extra-late flowering cultivars, such as 'Mardía', 'Marinada', 'Penta', 'Tardona', and 'Vairo', had the lowest inflection point estimates, which indicated that the period of steep fruit drop lasted significantly less time, suggesting that most of the drops occurred already at full bloom, which may be linked to either bud or flower abortion. It may be that these cultivars have poor flower quality, and/or poorer fruit set than other cultivars. On the other hand, cultivars such as 'Belona', 'Francoli', 'Largueta', and 'Marcona' had significantly higher inflection points than the average, which indicates longer periods of steep fruit drop. Therefore, each cultivar requires a different strategy in order to reduce the fruit drop and optimize cropping. Thus, depending on the cultivar profile, different management actions may need to be adopted. For instance, we could find four different scenarios in our study. First one was the case of 'Penta' which had a short period of steep fruit drop (most of the drop occurred a few days after full bloom, less than five days) and 
with low final cumulative fruit drop (70\%). Then we had the case of 'Tardona' which also had a short period of fruit drop, since the growth rate began to deaccelerate already at bloom (inflection point $=0$ ), but had high cumulative fruit drop $(>85 \%)$. A third scenario was the case of 'Belona', with long period of fruit drop (inflection point 20 days after full bloom) and lower cumulative fruit drop $(\sim 70 \%)$. The forth scenario was the case of 'Largueta' and 'Marcona', both with long period of fruit drop (more than 20 days after full bloom) and high final cumulative fruit drop $(\sim 90 \%)$. This suggests that management actions to reduce fruit drop should be adopted earlier on 'Tardona' and 'Penta' type than on 'Belona', 'Largueta', or 'Marcona' type. Hence, improving pollination and fruit set may have higher impacts on 'Tardona' than 'Largueta', whereas reducing fruit drop by lowering competition between fruits and carbohydrate deficits may have a better impact on 'Belona' rather than 'Penta'. Therefore, for cultivars that had high cumulative fruit drop already at bloom, actions should be taken before bloom or the year before in order to improve flower quality and fruit set.

Different fruit drop patterns and behaviors among cultivars may be attributed to diverse survival strategies, which can affect induction and differentiation (year before) and bloom, pollination, fruit set, and fruit growth (current year). However, this was not the purpose of this study, and further research needs to be done in order to explain what triggered the fruit drop at each timing.

Since different factors may be the cause of fruit drop depending on the period that they occur, adopting management practices in order to reduce fruit drop will depend on how and when they need to be applied. Fruit drops before bloom may be due to flowers that were not fully developed before opening [14]. In fruit species, drops that take place during bloom or shortly thereafter have been related to defective flowers, poor setting, and carbohydrate depletion, associated with mild winters [14,32-36]. In addition, environmental factors, such as temperature, may also affect pollen germination [11] and, thus, flower drop. On the other hand, drops that occur 40-50 days after full bloom have been attributed to competition between fruits and vegetative parts that affect carbon and hormone balances [12,14,37-41].

Rootstocks also had an important effect on the fruit drop patterns, with different effects depending on the cultivar. Overall, for both cultivars there were no significant differences among rootstocks regarding the fruit drop rate or the length of the mentioned fruit drop period. On the other hand, rootstocks had an effect on the final cumulative fruit drop. For 'Marinada', Rootpac ${ }^{\circledR} \mathrm{R}$ had less cumulative drop than the average, whereas for 'Vairo', Rootpac ${ }^{\circledR} \mathrm{R}$ was amongst the rootstocks with highest cumulative drop, and IRTA 1 the one with the lowest. These differences may be attributed to how the rootstocks affect the different low-medium vs high inherited vigor of the cultivar. For instance, based on our results, the most vigorous cultivar ('Vairo') budded onto one of the most vigorous rootstocks (INRA GF-677 and Rootpac ${ }^{\circledR} \mathrm{R}$ ) tended to have higher cumulative fruit drop and higher relative fruit drop rates, suggesting that vigor enhances fruit drop. Similar behavior was also observed for a less vigorous cultivar such as 'Marinada', when the higher vigorous rootstocks as INRA GF-677, IRTA 2, and Rootpac ${ }^{\circledR} R$ were among the ones with higher cumulative fruit drop.

Rootstock effects on cultivar performance have been widely reported [27,42,43], and even how rootstocks affect the hormonal profile of the scion has also been observed in other tree crops, like apple and other Prunus [44-46]. Thus, since fruit drop is related to carbohydrate and hormonal balances $[33,38,40,41]$, we may expect that rootstocks affect the fruit drop pattern, as seen in this study. Thus, as suggested, the higher the vigor of the combination cultivar $\times$ rootstock, the higher the fruit drop.

Tree management such as pruning type had also an important effect on fruit drop rate, length of fruit drop period, and cumulative fruit drop. When comparing different pruning types with the same rootstock and under the same input management (P3), fruit drop rates and cumulative fruit drop for both cultivars ('Marinada' and 'Vairo') tended to be lower when short pruning was performed. However, there were some nuances to this. 
For instance, for vigorous cultivars such as 'Vairo', final cumulative fruit drop responded similarly to long pruning and no pruning; whereas for less vigorous cultivars such as 'Marinada', long pruning had a more similar effect to short pruning than no pruning at all.

Pruning can have a large effect on the number of buds and the crop load. According to our results, short pruning significantly reduced the final cumulative fruit drop. In this regard, pruning type may have had greater effect on the carbohydrate balance than the number of flowers.

In some cases, the highest cumulative fruit drop coincided with the lowest yields ('Marinada' onto Cadaman or 'Vairo' with long pruning); whereas in other cases highest yields also occurred when high cumulative and fruit drop rates were observed ('Marinada' onto Rootpac ${ }^{\circledR} 20$ or INRA GF-677, or 'Vairo' with no pruning). Tombesi, Lampinen, Metcalf, and DeJong [8] reported yield to be also dependent on the number of flowers produced, the percentage of fruit set, and fruit weight. Therefore, reducing the final cumulative fruit drop and its fruit drop rate will not be the unique solution when aiming for yield increase.

\section{Conclusions}

This study showed different fruit drop patterns depending on the cultivar. Cumulative fruit drop for all cultivars had a logistic response with time. Overall, this relationship was very high, with most of the $\mathrm{R}^{2}$ values $>85 \%$. Rootstocks and pruning type also had an important effect on the fruit drop pattern, with differing effects depending on the scion cultivar and its inherited vigor. Overall, cumulative flower and fruit drop ranged from 50\% to $90 \%$ among cultivars and treatments, and the main fruit drop occurred from 20-60 days from full bloom (DFFB).

According to the different cultivar profiles regarding cumulative fruit drop, growth rates, and days from full bloom that fruit drop occurs, different actions and at different timing should be taken in order to reduce almond drop and optimize crop. Therefore, we may summarize the strategies to reduce fruit drop into three different groups. When the aim is to reduce the drop of buds and flowers, actions should be taken already the year before, when flower induction and differentiation takes place. When aiming to reduce fruit drop between full bloom and early petal fall, actions should address improving pollination and fruit set. When looking to reduce fruit drop, actions should be adopted to reduce carbon resource competition between reproductive growth and other functions. For further understanding of organ drops in almond, the combination of different management strategies and their impact on the cumulative fruit drop should be studied.

Author Contributions: Conceptualization, X.M. and M.R.; formal analysis, J.L. and X.M.; investigation, X.M., J.L. and L.T.; data curation, L.Z., X.M. and J.L.; writing—original draft preparation, J.L. and X.M.; writing-review and editing, J.L., X.M., I.B., M.R. and T.D.; supervision, X.M. All authors have read and agreed to the published version of the manuscript.

Funding: This research received no external funding.

Data Availability Statement: The data presented in this study are available on request from the corresponding author.

Acknowledgments: We thank Ramon Girabet, Marta Maldonado, and Guillem Martínez for field and laboratory support. We would also like to thank Ignacio Romagosa for statistical advice.

Conflicts of Interest: The authors declare no conflict of interest.

\section{References}

1. Gradziel, T.M.; Curtis, R.; Socias i Company, R. Almonds: Botany, Production and Uses. In Almonds: Botany, Production and Uses; CABI: Boston, MA, USA, 2017; pp. 70-86.

2. Batlle, I.; Dicenta, F.; Socias i Company, R.; Gradziel, T.M.; Wirthensohn, M.; Duval, H.; Vargas, F.J. Classical genetics and breeding. In Almonds: Botany, Production and Uses; Rafel Socias i Company, Gradziel, T.M., Eds.; CABI: Boston, MA, USA, 2017 ; pp. 111-148.

3. Socias i Company, R.; Gomez Aparisi, J.; Alonso, J.; Rubio-Cabetas, M.; Kodad, O. Retos y perspectivas de los nuevos cultivares y patrones de almendro para un cultivo sostenible. Inf. Técnica Econó. Agrar. 2009, 105, 99-116. 
4. Almond Board of Australia. Almond Insights 2019-2020; Australian Almonds: Loxton, Australia, 2020.

5. Almond Board of California. Almond Almanac 2019; California Almonds: Modesto, CA, USA, 2020.

6. MAPAMA. Anuario de Estadística Agraria 2019; Ministerio de Pesca, Agricultura y Alimentación, Gobierno de España: Madrid, Spain, 2020.

7. Miarnau, X.; Torguet, L.; Zazurca, L.; Maldonado, L.; Girabet, R.; Batlle, I.; Rovira, M. El futuro del almendro en España: ¿Será posible producir $4.000 \mathrm{~kg}$ de grano/ha? Horticultura 2018, 337, 16-26.

8. Tombesi, S.; Lampinen, B.D.; Metcalf, S.; DeJong, T.M. Yield in almond is related more to the abundance of flowers than the relative number of flowers that set fruit. Calif. Agric. 2017, 71, 68-74. [CrossRef]

9. Kodad, O.; Socias i Company, R. Flower age and pollenizer could affect fruit set in late-blooming self-compatible almond cultivars under warm climatic conditions. Sci. Hortic. 2013, 164, 359-365. [CrossRef]

10. Maita, S.; Sotomayor, C. The effect of three plant bioregulators on pollen germination, pollen tube growth and fruit set in almond [Prunus dulcis (Mill.) DA Webb] cvs. Non Pareil and Carmel. Electron. J. Biotechnol. 2015, 18, 381-386. [CrossRef]

11. Sorkheh, K.; Shiran, B.; Rouhi, V.; Khodambashi, M.; Wolukau, J.; Ercisli, S. Response of in vitro pollen germination and pollen tube growth of almond (Prunus dulcis Mill.) to temperature, polyamines and polyamine synthesis inhibitor. Biochem. Syst. Ecol. 2011, 39, 749-757. [CrossRef]

12. Tombesi, S.; Lampinen, B.D.; Metcalf, S.; DeJong, T.M. Spur fruit set is negatively related with current-year spur leaf area in almond. HortScience 2015, 50, 322-325. [CrossRef]

13. The Almond Doctor. Available online: https://thealmonddoctor.com/2016/03/07/almond-set-and-nut-drop/ (accessed on 12 February 2021).

14. Kester, D.E.; Griggs, W. Fruit setting in the almond: The pattern of flower and fruit drop. Proc. Am. Soc. Hort. Sci. 1959, 74, 214-219.

15. Vargas, F.J.; Romero, M.; Clavé, J.; Vergés, J.; Santos, J.; Batlle, I. 'Vairo', 'Marinada', ‘Constantí', and ‘Tarraco' almonds. HortScience 2008, 43, 535-537. [CrossRef]

16. Vargas, F.J.; Romero, M.A. Masbovera, Glorieta, and Francolí, three new almond varieties from IRTA. Acta Hortic. 1994, 373, 75-82. [CrossRef]

17. Dicenta, F.; Sánchez-Pérez, R.; Rubio, M.; Egea, J.; Batlle, I.; Miarnau, X.; Palasciano, M.; Lipari, E.; Confolent, C.; Martínez-Gómez, P. The origin of the self-compatible almond 'Guara'. Sci. Hortic. 2015, 197, 1-4. [CrossRef]

18. Felipe, A.J.; Socias i Company, R. 'Ayles', 'Guara', and 'Moncayo' almonds. HortScience 1987, 22, 961-962.

19. Socias i Company, R.; Felipe, A. 'Belona' and 'Soleta' almonds. HortScience 2007, 42, 704-706. [CrossRef]

20. Dicenta, F.; Cremades, T.; Martínez-García, P.J.; Martínez-Gómez, P.; Ortega, E.; Rubio, M.; Sánchez-Pérez, R.; López-Alcolea, J.; Egea, J. Penta and Makako: Two extra-late flowering self-compatible almond cultivars from CEBAS-CSIC. HortScience 2018, 53, 1700-1702. [CrossRef]

21. Egea, J.; Dicenta, F.; Berenguer, T.; García, J. 'Antoñeta' and 'Marta' almonds. HortScience 2000, 35, 1358-1359. [CrossRef]

22. Grasselly, C. Avijor 'Lauranne'. L'Arboriculture Fruit. 1991, 436, 75.

23. Grasselly, C.; Duval, H. L'amandier; CTIFL: Paris, France, 1997.

24. Felipe, A. El Almendro. I El Material Vegetal; Integrum: Lleida, Spain, 2000.

25. Bernhard, R.; Grasselly, C. Les pêchers x amandiers. Arboric. Fruit 1981, 328, 37-42.

26. Vargas, F.J.; Romero, M.A.; Clavé, J.; Batlle, I.; Miarnau, X.; Alegre, S. Important traits in IRTA's new almond cultivars. Acta Hortic. 2011, 912, 359-365. [CrossRef]

27. Lordan, J.; Zazurca, L.; Maldonado, M.; Torguet, L.; Alegre, S.; Miarnau, X. Horticultural Performance of 'Marinada' and 'Vairo' Almond Cultivars Grown on a Genetically Diverse Set of Rootstocks. Sci. Hortic. 2019, 256, 1-12. [CrossRef]

28. Felipe, A.; Gomez-Aparisi, J.; Vargas, F.; Romero, M.; Monastra, F.; Caboni, E.; Simeone, A.; Isaakidis, A. Obtention et selection de porte-greffe pour l'amandier multiplies par voie vegetative. Opt. Mediterr. N 1997, 16, 73.

29. Xarxa Agrometeorològica de Catalunya (XAC) and Servei Meteorològic de Catalunya. Available online: https: / www.ruralcat. net/web/guest/agrometeo.estacions (accessed on 20 April 2021).

30. Allen, R.G.; Pereira, L.S.; Raes, D.; Smith, M. FAO Irrigation and drainage paper No. 56. Rome Food Agric. Organ. U. N. 1998, 56, e156.

31. Felipe, A. Estados fenológicos del almendro. Inf. Tec. Econ. Agrar. 1977, 8, 8-9.

32. Brown, D. Climate in relation to decidious fruit production in California. IV. Effect of the mild winter of 1950-1951 on decidious fruits in northern California. Proc. Am. Soc. Hortic. Sci. 1952, 59, 111-118.

33. Lordan, J.; Reginato, G.; Lakso, A.; Francescatto, P.; Robinson, T. Natural fruitlet abscission as related to apple tree carbon balance estimated with the MaluSim model. Sci. Hortic. 2019, 247, 296-309. [CrossRef]

34. Jackson, J.; Hamer, P. The causes of year-to-year variation in the average yield of Cox's Orange Pippin apple in England. J. Hortic. Sci. 1980, 55, 149-156. [CrossRef]

35. Jackson, J.; Hamer, P.; Wickenden, M. Effects of early spring temperatures on the set of fruits of Cox's Orange Pippin apple and year-to-year variation in its yields. Acta Hortic. 1983, 139, 75-82. [CrossRef]

36. Lakso, A. Importance of climate and microclimate to yield and quality in horticultural crops. In Proceedings of the Agrometeorology: 2nd International Cesena Agricultura Conference, Cesena, Italy, 8-9 October 1987. 
37. Luckwill, L. Studies of fruit development in relation to plant hormones: I. Hormone production by the developing apple seed in relation to fruit drop. J. Hortic. Sci. 1953, 28, 14-24. [CrossRef]

38. Koukourikou-Petridou, M.A. The relation between the levels of extractable and diffusible IAA in almond fruits and their "June drop". Plant Growth Regul. 2003, 39, 107-112. [CrossRef]

39. Lordan, J.; Reginato, G.H.; Lakso, A.N.; Francescatto, P.; Robinson, T.L. Modelling physiological and environmental factors regulating relative fruit set and final fruit numbers in apple trees. J. Hortic. Sci. Biotechnol. 2020, 95, 600-616. [CrossRef]

40. Valdebenito, D.; Tombesi, S.; Tixier, A.; Lampinen, B.; Brown, P.; Saa, S. Spur behavior in Almond trees (Prunus dulcis [Mill.] DAWebb): Effects of flowers, fruit, and "June drop" on leaf area, leaf nitrogen, spur survival and return bloom. Sci. Hortic. 2017, 215, 15-19. [CrossRef]

41. Racskó, J.; Leite, G.; Petri, J.; Zhongfu, S.; Wang, Y.; Szabó, Z.; Soltész, M.; Nyéki, J. Fruit drop: The role of inner agents and environmental factors in the drop of flowers and fruits. Int. J. Hortic. Sci. 2007, 13, 13-23. [CrossRef]

42. Felipe, A. Rootstocks for almond. Present situation. In Options Mediterraneennes. Serie A. Séminaires Méditerranéens; CIHEAM: Zaragoza, Spain, 1989; Volume 5, pp. 13-18.

43. Yahmed, J.B.; Ghrab, M.; Mimoun, M.B. Eco-physiological evaluation of different scion-rootstock combinations of almond grown in Mediterranean conditions. Fruits 2016, 71, 185-193. [CrossRef]

44. Lordan, J.; Fazio, G.; Francescatto, P.; Robinson, T.L. Effects of apple (Malus $\times$ domestica) rootstocks on scion performance and hormone concentration. Sci. Hortic. 2017, 225, 96-105. [CrossRef]

45. Sorce, C.; Massai, R.; Picciarelli, P.; Lorenzi, R. Hormonal relationships in xylem sap of grafted and ungrafted Prunus rootstocks. Sci. Hortic. 2002, 93, 333-342. [CrossRef]

46. Tworkoski, T.; Miller, S. Endogenous hormone concentrations and bud-break response to exogenous benzyl adenine in shoots of apple trees with two growth habits grown on three rootstocks. J. Horticult. Sci. Biotechnol. 2007, 82, 960-966. [CrossRef] 